\title{
An epidemiological study of the respiratory health of workers in the European refractory ceramic fibre industry
}

H A Cowie, P Wild, J Beck, G Auburtin, C Piekarski, N Massin, J W Cherrie, J F Hurley, B G Miller, S Groat, C A Soutar

\begin{abstract}
Objectives-To investigate possible relations between respiratory health and past airborne exposure to refractory ceramic fibres (RCFs) and respirable dust in workers at six European factories, studied previously in 1987.

Methods-The target population comprised all current workers associated with RCF production, plus others who had participated in 1987 "leavers". Information was collected on personal characteristics, chest radiographs, lung function, respiratory symptoms, smoking, and full occupational history. Regression analysis was used to study relations between indices of health of individual workers and of cumulative exposure to airborne dust and fibres, and likely past exposure to asbestos.
\end{abstract}

Results and discussion-774 workers participated $(90 \%$ of current workers, $37 \%$ of leavers). Profusion of small opacities in exposed workers $(51 \% 0 / 1+; 8 \% 1 / 0+)$ was similar to that among an unexposed control group but higher than in new readings of the 1987 study films $(11 \% 0 / 1+, 2 \% 1 / 0+)$. The large difference between 1987 and recent films may be, at least in part, a reading artefact associated with film appearance. Small opacities of International Labour Organisation (ILO) category 1/0+ were not associated with exposure. An association of borderline significance overall between $0 / 1+$ opacities and exposure to respirable fibres was found for some exposure periods only, the time related pattern being biologically implausible. Pleural changes were related to age and exposure to asbestos, and findings were consistent with an effect of time since first exposure to RCFs. Among men, forced expired volume in 1 second $\left(F E V_{1}\right)$ and forced vital capacity (FVC) were inversely related to exposure to fibres, in current smokers only. $\mathrm{FEV}_{1} / \mathrm{FVC}$ ratio and transfer factor $\left(\mathrm{TL}_{\mathrm{co}}\right)$ were not related to exposures. The estimated restrictive effect was on average mild. Prevalence of respiratory symptoms was low. Chronic bronchitis and its associated symptoms (cough, phlegm) showed some association with recent exposure to respirable fibres. This could be due to an irritant effect of RCFs. (Occup Environ Med 2001;58:800-810)

H Cowie

hilary.cowie@iomhq.org.uk

Accepted 12 July 2001
In Europe, production of ceramic fibres began in the late 1960s and by 1986 seven plants manufactured ceramic fibre products in France, Germany, and the United Kingdom. Ceramic fibres are made by melting silica and alumina at around $2000^{\circ} \mathrm{C}$, with other minor components, and then blowing or spinning the melt into fibres. Most ceramic fibres are manufactured as blankets and they are generally used for high temperature insulation.

A study of workers in the European refractory ceramic fibre (RCF) industry in 1987 suggested that some aspects of respiratory ill health in employees were related to indices of exposure to airborne RCFs and other material. ${ }^{12}$ The following relations were reported: symptoms of breathlessness on exertion with cumulative exposure to both respirable fibres and respirable dust ${ }^{3}$; dry cough with intensity of current exposure; lung function deficits with cumulative exposure to respirable fibres, among current smokers only; small rounded opacities category $1 / 0$ with current exposures to non-respirable fibres and with time worked in the RCF industry. Neither pleural disease nor chronic bronchitis was related to exposure. Many of these relations are biologically plausible; the association between small rounded opacities and non-respirable fibres is not.

By contrast, similar studies in the United States indicated that pleural changes, although infrequent, might be related to exposure to RCFs, whereas only three subjects were classified as showing pulmonary parenchymal opacities category $1 / 0+.{ }^{4}$ Decreases in lung function were related to time spent in production, for smokers only. ${ }^{5}$

These results suggested the need for further research aimed primarily at obtaining a better understanding of the possible association between exposure of workers in the European ceramic fibre industry to airborne dust and fibres, and respiratory ill health. A second cross sectional study has therefore been conducted at the six remaining European plants manufacturing RCFs. The programme included medical surveys of most current and some past workers, occupational hygiene measurements of concentrations of airborne dust and fibre since 1995, a pilot study of methods to estimate past concentrations and the reconstruction of individual exposure indices. The study is reported here with the principal aim of clarifying the possible relations between respiratory health and indices of airborne exposure to refractory ceramic material. Tracing procedures have also been set up to allow a future study of the mortality of European RCF workers. 
The study, commissioned by the European Ceramic Fibres Industry Association, was a collaborative project led by the Institute of Occupational Medicine (IOM) in the United Kingdom, with the Institut National de Recherche et de Sécurité (INRS) and Institut National de l'Environnement Industriel et des Risques (INERIS) in France and the University of Köln in Germany. Ongoing epidemiological studies of RCF workers are also being conducted concurrently in the United States. This paper summarises the methods and results of the study. These are presented in more detail in Cowie et al, 1999. ${ }^{6}$

\section{Methods}

STUDY GROUP

This cross sectional morbidity study was carried out at six RCF plants: two in England, three in France, and one in Germany. Workers at these six plants were included in the previous study in 1987 . The target study population was defined as all workers current at the time of survey who were involved in production of ceramic fibres or on associated activities, plus others who had participated in the earlier (1987) survey and had since left the industry "leavers". A seventh plant, included in 1987, had subsequently closed; it was considered not practicable to study leavers from this plant.

\section{MEDICAL SURVEY}

The medical team used a mobile survey unit from the IOM at each plant and consisted of occupational physicians from each country, a British radiographer with acceptable language skills, a French lung function technician fluent in English and German, and fully trained local questionnaire administrators in each country. The following information was obtained from each participant: personal identification data, age, height, weight, chest radiograph, lung function, respiratory symptoms, smoking, and occupational history.

A detailed protocol covering quality assurance issues was produced and rigorously followed during the course of the study. This was particularly important because of the need for comparison of results between the three European countries in this study and the United States study. As well as technical procedures, the need to accommodate different national requirements for confidentiality, clinical reporting, etc was fulfilled.

\section{RADIOLOGY}

Full size $(40 \times 40 \mathrm{~cm})$ posteroanterior chest radiographs were taken using Polyphos 150 equipment with a moderately high (up to 125) $\mathrm{kV}$ technique. Films were developed immediately on site with an automated $3 \mathrm{M}$ XP510 processor and checked for radiographic technique and film quality, so that a repeat exposure could be made if necessary. All chest radiographs were subsequently interpreted clinically by a radiologist and results conveyed to the person concerned where necessary.

The chest radiographs were read epidemiologically according to the International Labour Organisation (ILO) (1980) classification. ${ }^{7}$ The radiographs were read independently, and in fully randomised order under identical conditions, by three highly experienced medical readers, one from each country, at INERIS in France. The results were recorded by a clerk. The standard set of ILO films was used for comparison by each reader. All films from this and the first study were included in the reading trial, plus 164 films from workers not exposed to dust. These 164 films were included to allow a comparison of the readings of the current reading panel with previous readings of the same films by some of the usual medical reading panel of the IOM, and to allow estimation of the prevalence of small opacities in an unexposed population from the readings of the current reading panel. The 1987 radiographs were visibly distinguishable due to smaller size and different technique, whereas the 164 films were similar in appearance to those from the current study.

The 164 films were a stratified selection from 300 radiographs of telecommunications workers, who had not worked in any dusty industries. The 300 films had been read previously by three medically qualified readers, and $21(7 \%)$ had been classified as $0 / 1$ or more by at least two of these three readers. These 21 films were selected in the 164 films included now, along with 143 of the other 279 films. Calculations of prevalences in the 164 films in the present study were done separately for the 21 and 143 films and weighted appropriately to estimate prevalence for the full set of 300 films.

The ILO $(1980)^{7}$ classification scheme was used to record, in particular, profusion and type of small opacities and the presence of pleural thickening and pleural plaques. Fifty trigger films, selected because they had been considered by previous readings to show radiographic changes (low profusions of irregular small opacities or pleural changes) and the classification of which had been jointly agreed on by the current readers in a prereading exercise, were inserted at intervals to help the readers maintain a consistent reading level. Once a trigger film had been classified by a reader, he was reminded by the clerk of the agreed classification.

\section{LUNG FUNCTION}

Spirometry was performed with a PK Morgan Spiro 232 rolling seal system: three technically satisfactory maximal forced exhalations were recorded and the best forced expiratory volume in one second $\left(\mathrm{FEV}_{1}\right)$ and forced vital capacity (FVC) were used for both clinical assessment and subsequent analysis. Single breath transfer factor for carbon monoxide $\left(\mathrm{TL}_{\mathrm{CO}}\right)$ and alveolar volume $\left(\mathrm{V}_{\mathrm{A}}\right)$ were measured in duplicate with a PK Morgan Transfer Test B system, as described by Quanjer, ${ }^{8}$ and the mean of the two values was used in the analysis. Participants were asked not to smoke for at least 1 hour before testing took place.

Carbon monoxide (CO) in exhaled breath was measured (Bedfont Smokerlyzer) to confirm smoking habit. If high $\mathrm{CO}$ concentrations were detected in declared non-smokers, they were asked again about their smoking habits. 
Table 1 Estimated arithmetic mean concentrations of respirable fibres (fibres. $\mathrm{ml}^{-1}$ ), 1995

\begin{tabular}{|c|c|c|c|c|c|c|c|}
\hline \multirow[b]{2}{*}{ Occupational group } & \multicolumn{6}{|l|}{ Plant } & \multirow[b]{2}{*}{ All } \\
\hline & 1 & 2 & 3 & 4 & 5 & 6 & \\
\hline Primary production & 0.089 & 0.160 & - & 0.346 & 0.393 & 0.376 & - \\
\hline Secondary production & 0.227 & 0.145 & 0.275 & - & 0.247 & - & - \\
\hline Conversion and finishing & - & 0.316 & 0.911 & 1.249 & 0.408 & 0.913 & - \\
\hline Ancillary & 0.030 & 0.075 & 0.320 & 0.167 & 0.177 & 0.139 & - \\
\hline Not exposed & - & - & - & - & - & - & 0.032 \\
\hline
\end{tabular}

RESPIRATORY SYMPTOMS

The respiratory symptoms questionnaire was developed and administered on personal computers with Pulsetrain's Bellview Questionnaire package. It was based partly on the American Thoracic Society (ATS) questionnaire ${ }^{9}$ and the United Kingdom Medical Research Council questionnaire. ${ }^{10}$ The questions cover symptoms and episodes of cough, phlegm, wheezing, breathlessness, and frequency and severity of past and recent chest illnesses. The ATS questionnaire was used in the concurrent United States study.

EXPOSURE ESTIMATION FOR RCF FIBRES AND DUST Cumulative lifetime exposure indices to $\mathrm{RCF}$ material were calculated from information on occupations in the RCF industry and estimated concentrations of respirable and nonrespirable fibres, and respirable and total dust. Methods and results are reported elsewhere ${ }^{11}$ and are summarised briefly below. The occupational history questionnaire was designed and administered on PC and recorded all jobs held since leaving school, both within and outside the RCF industry.

Time worked by each person in each recorded job within the RCF industry was allocated to one of five occupational groups: primary production; secondary production; conversion and finishing; ancillary workers (including maintenance, warehouse and shipping, cleaners); and non-exposed workers. Estimated average concentrations by plant and occupational group were calculated from the measurements made during the occupational hygiene surveys. Concentrations were estimated separately for 1987 and the current study with analysis of variance (ANOVA) methods to examine differences between plants, occupational groups, and any relevant interactions. Results from these analyses were used to estimate the average concentration for each exposure variable for each combination of plant and occupational group. Linear interpolation on the log scale was used to estimate concentrations between 1987 and the current study. Estimated concentrations for respirable fibres in 1995 are shown, as an example, in table 1.

Individual cumulative exposure estimates for respirable and non-respirable fibres, respirable and total dust during each year 1987-96 were derived by multiplying the time (years) spent in each occupational group by the estimated concentrations (fibres. $\mathrm{ml}^{-1}$ or $\mathrm{mg} \cdot \mathrm{m}^{-3}$ ) for that occupational group in that year at the relevant plant, and summing exposures across occupational groups. Time since first exposure to RCFs was calculated from the start date of the first job exposed to RCFs held by each study participant. Study participants who had never worked in jobs exposed to RCFs were assigned a time since first exposure of zero.

In the main analysis, estimated concentrations for 1987 were used for exposures before that period. Information from the pilot study to estimate past concentrations was available for only a few occupational groups at one plant, and was not used in formally estimating past concentrations.

The effects of exposures to dust or fibres experienced in different periods were also investigated; to examine the latency of effects of exposure on health end points. Cumulative exposures were subdivided into six time bands (before 1971, 1972-76, 1977-81, 1982-86, 1987-91, and 1992-96) designed to separate the unmeasured exposures before 1987 from those measured subsequently. If exposure to ceramic fibres did indeed cause or contribute to fibrosis in exposed workers, then any associated radiological or lung function changes, and some respiratory symptom effects, would be expected to develop slowly. At concentrations similar to those found in this study, ${ }^{11}$ these changes would not become apparent without several years of exposure; maybe 10 or more.

\section{OTHER RELEVANT EXPOSURES}

Each job at the plants was also classified according to whether or not it potentially involved exposure to asbestos, and the period during which such exposure may have taken place was identified. These classifications were based on an initial assessment of exposure to asbestos for the plants carried out by the IOM, supplemented by further information provided by the factory management. Workers were classified as potentially exposed to asbestos if they had worked in an exposed job during the relevant period. Four types of activity were judged to have led to possible notable exposure to asbestos: maintenance of equipment or building materials containing asbestos, wearing of asbestos protective clothing, manufacturing products containing asbestos, and using products containing asbestos. For each potentially exposed study participant time from initial exposure to asbestos and duration of exposure to asbestos were calculated. Detailed information on intensity of exposure to asbestos was not available.

The occupational histories collected at survey included information on all jobs held outside the RCF industry as well as RCF jobs. Lists of occupations which were identified as having potential exposure to asbestos were drawn up by one of us (JWC) and each job was assigned a code designating possible exposure to asbestos. Duration of time spent in these potentially exposed jobs, and time from initial exposure to asbestos outside the industry, were also calculated.

STATISTICAL METHODS

Informed by an understanding of possible mechanisms, statistical analyses systematically investigated a wide range of possible associations between respiratory health effects and various exposures. Radiology responses (prevalence of 
Table 2 Distribution of personal characteristics of study group by sex and country

\begin{tabular}{|c|c|c|c|c|c|c|c|c|}
\hline \multirow[b]{2}{*}{ Sex } & \multirow[b]{2}{*}{ Country } & \multirow[b]{2}{*}{ Group size (n) } & \multirow{2}{*}{$\begin{array}{l}\text { Age (mean (SD) } \\
y)\end{array}$} & \multirow{2}{*}{$\begin{array}{l}\text { Height (mean } \\
\text { (SD) } m \text { ) }\end{array}$} & \multirow{2}{*}{$\begin{array}{l}\text { Weight (mean } \\
\text { (SD) } \mathrm{kg} \text { ) }\end{array}$} & \multicolumn{3}{|c|}{ Smoking $(n(\%))$} \\
\hline & & & & & & Non-smokers & Current smokers & Ex-smokers \\
\hline \multirow[t]{4}{*}{ Men } & France & 309 & $40.5(10.8)$ & $1.73(0.07)$ & $75.2(12.4)$ & $103(33)$ & $128(41)$ & $78(25)$ \\
\hline & Germany & 49 & $41.2(10.2)$ & $1.77(0.07)$ & $83.6(16.0)$ & $13(27)$ & $27(55)$ & 9 (18) \\
\hline & UK & 334 & 43.5 (11.8) & $1.75(0.06)$ & $80.8(12.1)$ & $129(39)$ & $106(32)$ & $99(30)$ \\
\hline & All & 692 & $42.0(11.3)$ & $1.74(0.07)$ & $78.4(12.9)$ & $245(35)$ & $261(38)$ & $186(27)$ \\
\hline \multirow[t]{4}{*}{ Women } & France & 42 & $41.8(10.0)$ & $1.61(0.05)$ & $58.8(9.3)$ & $24(57)$ & $13(31)$ & $5(12)$ \\
\hline & Germany & 12 & $37.7(9.1)$ & $1.65(0.06)$ & $74.8(18.0)$ & $2(17)$ & $6(50)$ & $4(33)$ \\
\hline & UK & 28 & $36.6(11.3)$ & $1.63(0.04)$ & $63.7(15.6)$ & $21(75)$ & $5(18)$ & $2(7)$ \\
\hline & All & 82 & $39.4(10.5)$ & $1.62(0.05)$ & $62.8(14.1)$ & $47(57)$ & $24(29)$ & $11(13)$ \\
\hline
\end{tabular}

small opacities and pleural changes) and respiratory symptoms were analysed relative to respirable fibres and respirable dust; lung function spirometry $\left(\mathrm{FEV}_{1}, \mathrm{FVC}\right.$ and their ratio), and transfer factor $\left(\mathrm{T}_{\mathrm{L}} \mathrm{co}\right.$ and $\left.\mathrm{V}_{\mathrm{A}}\right)$ were examined relative to respirable and non-respirable fibres, and respirable and total dust.

The relations between health effects and occupational exposures were examined separately with regression methods: linear models ${ }^{12}$ for variables measured on continuous scalessuch as lung function-and logistic models ${ }^{13}$ for binary responses-such as respiratory symptoms. General curvilinear relations, fitted as general additive models ${ }^{14}$ were also considered, but did not add anything to the models and are not reported here. Analyses were carried out for the full study group, and also excluding people potentially exposed to asbestos in the RCF or other industries, or to silica outside the RCF industry, which might have affected lung health. Measured concentrations of silica within the RCF industry were negligible and so individual exposures to silica were not calculated.

\section{Results}

STUDY GROUP

Out of 1006 subjects eligible for medical survey, a total of 774 people attended, of whom 692 were men and 82 women. This represented $90 \%$ of eligible current workers and $37 \%$ of leavers. The lowest response rates were among the younger leavers, whom we consider are most likely to have left the area to work elsewhere. Of the attendees $166(21 \%)$ had worked at any of the six plants for 20 years or more.

The characteristics of those examined are shown in table 2 . The table shows detailed differences, but broad similarity between the groups. The proportion of current smokers in Germany was relatively high.

ESTIMATED EXPOSURE TO DUSTS AND FIBRES On average attendees had worked at the plants for 13 years, with average time in production jobs of around 8 years. The mean (range) estimated cumulative exposure index for respirable fibres was $4.9(0.01-36)$ f. $\mathrm{ml}^{-1} . \mathrm{y}$, and for non-respirable fibres it was $0.7(0.001-5.0)$ f. $\mathrm{ml}^{-1}$.y. Both measures of fibre exposure were higher in production jobs and among smokers

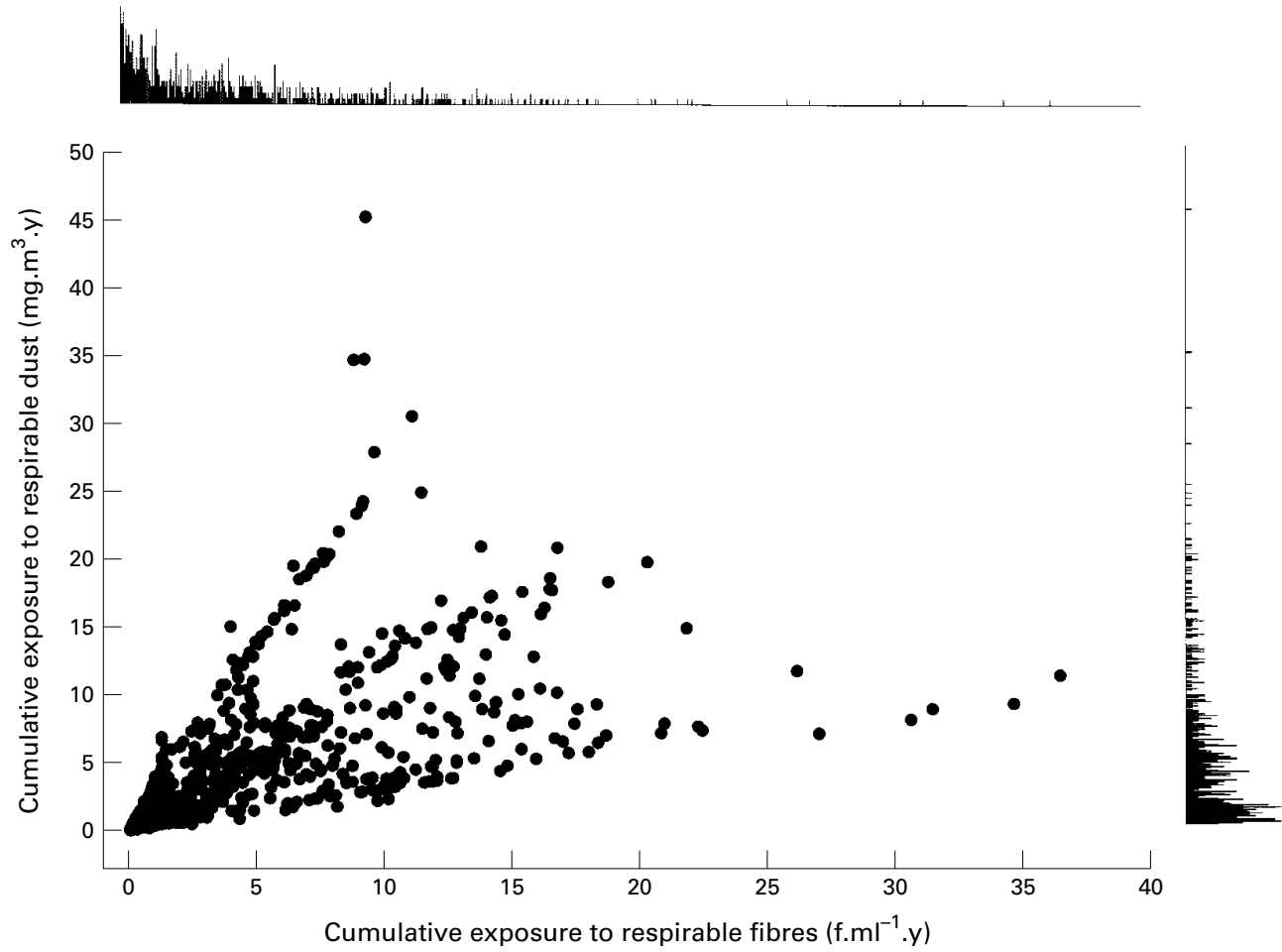

Figure 1 foint and marginal distributions of cumulative exposure indices for respirable fibres and respirable dust 
Table 3 Mean exposure to respirable and non-respirable fibres $\left(f . m l^{-1} \cdot y\right)$ respirable and total dust $\left(m g . m^{-3} \cdot y\right)$ and mean years in production jobs, within periods (subjects with non-zero exposure in each period and thus contributing to the mean are shown)

\begin{tabular}{|c|c|c|c|c|c|c|c|c|}
\hline Period & $\begin{array}{l}\text { Subjects } \\
\text { exposed to } \\
\text { fibres }(n)\end{array}$ & $\begin{array}{l}\text { Mean exposure to } \\
\text { respirable fibre }\end{array}$ & $\begin{array}{l}\text { Mean exposure to } \\
\text { non-respirable } \\
\text { fibre }\end{array}$ & $\begin{array}{l}\text { Subjects } \\
\text { exposed to } \\
\text { dust }(n)\end{array}$ & $\begin{array}{l}\text { Mean exposure to } \\
\text { respirable dust }\end{array}$ & $\begin{array}{l}\text { Mean total } \\
\text { exposure to dust }\end{array}$ & $\begin{array}{l}\text { Subjects in } \\
\text { production jobs } \\
\text { (n) }\end{array}$ & $\begin{array}{l}\text { Mean duration in } \\
\text { production }(n)\end{array}$ \\
\hline Before 1971 & 59 & 0.88 & 0.12 & 91 & 1.93 & 4.98 & 28 & 2.88 \\
\hline $1971-76$ & 190 & 1.22 & 0.17 & 188 & 1.44 & 4.43 & 95 & 2.38 \\
\hline $1977-81$ & 359 & 1.92 & 0.29 & 346 & 2.02 & 6.12 & 186 & 3.74 \\
\hline $1981-86$ & 476 & 2.05 & 0.31 & 457 & 2.16 & 6.52 & 251 & 3.80 \\
\hline $1987-91$ & 630 & 1.66 & 0.24 & 606 & 1.75 & 5.29 & 327 & 3.98 \\
\hline $1992-96$ & 746 & 1.06 & 0.15 & 718 & 0.96 & 3.13 & 400 & 3.91 \\
\hline
\end{tabular}

and ex-smokers, proportionally more of whom worked in production jobs. The mean (range) exposure for total dust was 15.9 (0.05-79) $\mathrm{mg} \cdot \mathrm{m}^{-3} . \mathrm{y}$ and for respirable dust it was 5.2 (0.02-45) mg.m $\mathrm{m}^{-3} \cdot \mathrm{y}$.

Figure 1 shows the marginal distributions of the exposures for respirable fibres and respirable dust and their joint distribution. Both variables show the typical skewed distribution of cumulative exposures with most of the subjects having low exposures, and a few with higher exposures. The four exposure indices were all correlated, with the strongest association occurring between respirable and nonrespirable fibres (correlation coefficient 0.93). For comparison, the correlation coefficient for the association between total and respirable dust exposures was 0.61 , between respirable fibres and respirable dust 0.58 , and between respirable fibres and total dust 0.82 .

Table 3 shows average exposures, and time spent in production jobs (primary production, secondary production, secondary conversion, and finishing), by period. All exposures before 1987 were based on the concentrations measured during 1987. Cumulative exposures experienced before 1976 were generally low, reflecting the shorter times spent in production jobs when the industry was starting up, and when much of the exposure to RCFs was from ancillary jobs where the fibre concentrations were lower than in production jobs. Relatively low exposures in recent years reflect reductions in concentrations since 1987.

Of the 774 participants, 158 (20\%) were classified as potentially exposed to asbestos within the RCF industry. The proportion exposed at each plant ranged from $10 \%$ to around $30 \%$. These subjects tended to be older and also to have higher exposures to non-asbestos fibres, and to respirable and total dust because the use of asbestos was greater in the early years of the industry; $88(56 \%)$ of the 158 had been in the industry for 20 years or more. Forty five per cent

Table 4 Distribution of median profusion of small opacities for men in the current study, by age and smoking ( $n$ (\% within each age and smoking group))

\begin{tabular}{lllllrrr}
\hline \multicolumn{7}{c}{ Age } \\
\cline { 3 - 8 } Smoking & Profusion & $<25$ & $25-34$ & $35-44$ & $45-54$ & $\geqslant 55$ & \multicolumn{1}{c}{ All } \\
\hline \multirow{2}{*}{ Non-smokers } & $0 / 0$ & $10(77)$ & $48(63)$ & $36(58)$ & $29(49)$ & $16(53)$ & $139(58)$ \\
& $0 / 1$ & $3(23)$ & $27(36)$ & $24(39)$ & $29(49)$ & $12(40)$ & $95(40)$ \\
& $1 / 0+$ & $0(0)$ & $1(1)$ & $2(3)$ & $1(2)$ & $2(7)$ & $6(3)$ \\
Current smokers & $0 / 0$ & $16(80)$ & $33(44)$ & $33(36)$ & $13(32)$ & $3(10)$ & $98(38)$ \\
& $0 / 1$ & $4(20)$ & $39(52)$ & $48(52)$ & $19(46)$ & $14(47)$ & $124(48)$ \\
& $1 / 0+$ & $0(0)$ & $3(4)$ & $11(12)$ & $9(22)$ & $13(43)$ & $36(14)$ \\
Ex-smokers & $0 / 0$ & $2(67)$ & $14(61)$ & $21(39)$ & $21(35)$ & $14(33)$ & $72(39)$ \\
& $0 / 1$ & $1(33)$ & $9(39)$ & $32(59)$ & $33(55)$ & $19(44)$ & $94(51)$ \\
& $1 / 0+$ & $0(0)$ & $0(0)$ & $1(2)$ & $6(10)$ & $10(23)$ & $17(9)$ \\
\hline
\end{tabular}

of attendees (351 subjects, including 98 who were also exposed within the industry) were potentially exposed to asbestos outside the industry, but by contrast with those exposed within the RCF plants, there was little difference in the exposure to RCFs between the groups potentially exposed and not exposed to asbestos.

RADIOLOGY: SMALL OPACITIES

All three readers reported a higher prevalence of small opacities in the external control group of non-exposed workers ( $51 \%$ profusion $0 / 1+$ ) than a different panel who read the same films previously $(7 \%$ profusion $0 / 1+)$. The prevalence of small opacities with profusion $0 / 1+$ was $51 \%$ in the study population exposed to RCFs, which was the same as the prevalence in the external group of non-exposed workers. This prevalence was much higher than that found in the earlier (1987) films of RCF workers, where only $11 \%$ were classified with $0 / 1+$ opacities, as re-read in this study, and $13 \%$ classified as $0 / 1+$ in the 1987 readings of the same films by a different film reading panel.

Overall, the quality of the radiographs was satisfactory with $74 \%$ of the 1996 radiographs and $63 \%$ of the 1987 radiographs classified as 1 , good, or 2, acceptable, according to the ILO rating system. The pattern of prevalences found in the 1996 and 1987 radiographs was unchanged when comparisons were restricted to radiographs of quality 1 and 2 .

As the highest median profusion among the relatively few women in the study group was $0 / 1$ (in 14 out of 74 with radiographs), the statistical analyses reported here were restricted to men.

Among men, prevalence of small opacities was higher among current smokers and increased with age (table 4). Most opacities at each level of profusion were predominantly irregular in shape, with each of the three readers classifying more than $85 \%$ of films with opacities as irregular. Only eight films, three profusion $0 / 1$ and five profusion $1 / 0$, showed predominantly rounded opacities, all from current smokers. Large opacities were seen on one film, by all readers, on a background of category $1 / 1$ for small opacities. Logistic regression modelling was carried out for two end points, $1 / 0+$ and $0 / 1+$ small opacities.

Small opacities category $1 / 0+$ were significantly associated with smoking, with an odds ratio (OR) of 5.7 (95\% confidence interval (95\% CI) 2.1 to 15.6 ) for current smokers compared with non-smokers and 2.5 (95\% CI 0.9 to 6.7) for ex-smokers compared with nonsmokers. Profusion of $1 / 0+$ opacities roughly doubled for each 10 year increase in age (OR $2.2,95 \%$ CI 1.6 to 3.1 ). Table 5 shows the ORs 
Table 5 Results from logistic regression analysis of profusion of small opacities $1 / 0+$ and $0 / 1+$

\begin{tabular}{|c|c|c|}
\hline & $1 / 0+$ opacities & $0 / 1+$ opacities \\
\hline & OR $(95 \% C I)$ & OR $(95 \% C I)$ \\
\hline Respirable fibres (f.ml $\left.{ }^{-1} \cdot y\right)$ & $1.02(0.76$ to 1.37$)$ & $1.18(0.98$ to 1.43$)$ \\
\hline Respirable dust $\left(\mathrm{mg} \cdot \mathrm{m}^{-3} \cdot \mathrm{y}\right)$ & $1.20(0.94$ to 1.54$)$ & \\
\hline Non-smokers & & $0.86(0.62$ to 1.20$)$ \\
\hline Current smokers & & 1.45 (0.99 to 2.12$)$ \\
\hline Ex-smokers & & $1.22(0.89$ to 1.67$)$ \\
\hline Time in production $(y)$ & $1.01(0.85$ to 1.20$)$ & $1.14(1.02$ to 1.27$)$ \\
\hline
\end{tabular}

ORs (95\% CIs) are for a mean difference of 5 units in exposure after adjustment for age, smoking, and cumulative amount smoked. Exposure variables were fitted in separate models. Where effects differ significantly between smoking groups, these are shown separately

Table 6 Results from regression analysis of classification 0/1+ small opacities for men

\begin{tabular}{lll}
\hline & Respirable fibres $\left(f . \mathrm{ml}^{-1} \cdot y\right)$ & Duration in production $(y)$ \\
\hline Up to 1971 (per 1 unit) & $1.54(0.81$ to 2.96$)$ & $1.31(0.90$ to 1.90$)$ \\
$1972-76$ (per 1 unit) & $1.06(0.83$ to 1.34$)$ & $1.16(0.95$ to 1.41$)$ \\
$1977-81$ (per 1 unit) & $1.03(0.90$ to 1.17$)$ & $1.05(0.95$ to 1.16$)$ \\
$1982-86$ (per 1 unit) & $1.06(0.95$ to 1.18$)$ & $1.05(0.97$ to 1.14$)$ \\
$1987-91$ (per 1 unit) & $1.13(1.00$ to 1.29$)$ & $1.09(1.01$ to 1.17$)$ \\
$1992-96$ (per 1 unit) & $1.28(1.05$ to 1.55$)$ & $1.11(1.03$ to 1.20$)$ \\
\hline
\end{tabular}

${ }^{\star}$ ORs (95\% CIs) are calculated from model also containing terms for age, smoking, and amount smoked. Each period fitted in a separate regression model.

for the association between small opacities and cumulative exposure indices for fibres and dust, after adjustment for age and smoking. There was some correlation between the three time related variables in the model (age, cumulative amount smoked, and cumulative exposure to fibres) but the correlation coefficients were relatively low (ranging from 0.278 to 0.373 ). There was no evidence of an association between small opacities category $1 / 0+$ and lifetime exposure to fibres or to time in production, whereas the OR for dust was increased but not significant.

Examination of the association between opacities category $1 / 0+$ and exposure subdivided by calendar period showed a positive association with exposure experienced before 1971 , but no evidence of association with later exposures.

Prevalence of small opacities of category $0 / 1+$ was higher among current smokers (OR $2.4,95 \%$ CI 1.6 to 3.5 ) and ex-smokers (OR $1.7,95 \%$ CI 1.1 to 2.7 ) than non-smokers. Profusion of $0 / 1+$ opacities increased by around $20 \%$ for each 10 year increase in age among non-smokers (OR 1.2, 95\% CI 1.0 to 1.5) and almost doubled for each 10 year increase in age among current smokers (OR $1.9,95 \%$ CI 1.4 to 2.5$)$. An association between $0 / 1+$ opacities and exposure to respirable fibres was of borderline significance (table 5); a more significant association was found with total years spent in production. For respirable dust, the association differed significantly between smoking groups and was strongest and close to significance among current smokers.

Examination of the associations with exposure over period showed that the largest effects were for the earliest years (up to 1971); then to a lesser extent for the most recent years, and weakest for the intervening period (table 6). This pattern was evident both for years in production and exposure to respirable fibre. Analysis of the relations with respirable dust by
Table 7 Prevalence of pleural plaques (number with plaques/total number in cell (\% with plaques)) in subjects not exposed to asbestos

\begin{tabular}{lllll}
\hline $\begin{array}{l}\text { Time since first } \\
\text { exposure to } \\
\text { refractory } \\
\text { ceramic fibre } \\
(y)\end{array}$ & Age & & & \\
\cline { 2 - 5 } & $<45$ & $45-54$ & $\geqslant 55$ & All \\
\hline 0 & $0 / 38(0)$ & $0 / 16(0)$ & $0 / 2(0)$ & $0 / 56(0)$ \\
$<10$ & $0 / 122(0)$ & $1 / 12(8)$ & $0 / 6(0)$ & $1 / 140(1)$ \\
$10-19$ & $0 / 82(0)$ & $3 / 25(12)$ & $3 / 16(19)$ & $6 / 123(5)$ \\
$\geqslant 20$ & $0 / 15(0)$ & $1 / 12(8)$ & $1 / 9(11)$ & $2 / 36(6)$ \\
All & $0 / 257(0)$ & $5 / 65(8)$ & $4 / 33(12)$ & $9 / 355(3)$ \\
\hline
\end{tabular}

Table 8 Results from logistic regression analysis of pleural plaques and pleural changes for subjects not exposed to asbestos

\begin{tabular}{lll}
\hline & $\begin{array}{l}\text { Model including age } \\
\text { OR (95\% CI) }\end{array}$ & $\begin{array}{l}\text { Model excluding age } \\
\text { OR }(95 \% \text { CI })\end{array}$ \\
\hline $\begin{array}{l}\text { Pleural plaques } \\
\text { Pleural changes }\end{array}$ & $2.03(0.78$ to 5.25$)$ & $4.01(1.54$ to 10.44$)$ \\
\hline $\begin{array}{l}\text { ORs are expressed/10 y since first exposure to refractory } \\
\text { ceramic fibre. }\end{array}$
\end{tabular}

period showed that the associations with most recent exposures were strongest (results not shown here).

Analyses of the few radiographs classified with predominantly rounded small opacities showed significant associations between $0 / 1+$ rounded opacities and estimated cumulative exposure to respirable dust, and between 1/0+ rounded opacities and exposure to both respirable fibres and respirable dust. For both profusion levels, associations were strongest with most recent exposures to respirable fibres.

\section{RADIOLOGY: PLEURAL CHANGES}

Pleural changes of any kind were classified by two or more readers on $78(11 \%)$ of the radiographs from the current study, and pleural plaques in particular on $40(5 \%)$. Five of those with general pleural changes had costophrenic angle obliteration only. Prevalences were lower ( $9 \%$ pleural changes, $3 \%$ pleural plaques) among the 355 radiographs from people with recorded occupations which did not suggest potential exposure to asbestos. Both pleural plaques and pleural changes were positively associated with increasing age and pleural changes were also associated with increasing body mass index (weight divided by height squared).

Overall among the 355 workers unexposed occupationally to asbestos, the prevalence of pleural plaques (table 7) and pleural changes increased with increasing time since first exposure to RCFs. Statistical modelling, without adjusting for age, showed a highly significant association between time since first exposure to RCFs and both pleural changes and pleural plaques (table 8). For pleural plaques, the more specific indicator, the trend was not clear within age groups, but evidence was based on only nine cases (table 7). Further modelling confirmed that, after adjusting for age, smoking, and (for pleural changes) body mass index, the association was weaker for both pleural plaques and pleural changes and was significant for pleural changes only (table 8). Results for pleural changes were insensitive to the 
Table 9 Spirometry (men) (association with age, smoking, physique, and country)

\begin{tabular}{lcc}
\hline & $F E V_{1}(l)$ & $F V C(l)$ \\
\hline Constant ${ }^{\star}$ & $3.79(82.1)$ & $4.90(92.0)$ \\
Age (y) & $-0.029(-8.7)$ & $-0.025(-6.5)$ \\
Height $(\mathrm{cm})$ & $0.037(7.6)$ & $0.058(10.4)$ \\
Weight $(\mathrm{kg})$ & $-0.003(-1.5)$ & $-0.005(-2.4)$ \\
Current smokers $v$ non-smokers $\dagger$ & $-0.158(-3.2)$ & $-0.096(-1.7)$ \\
Ex-smokers $v$ non-smokers $\dagger$ & $-0.010(-0.2)$ & $0.003(0.0)$ \\
Add age for current smokers & $-0.003(-0.7)$ & $0.002(0.3)$ \\
Add age for ex-smokers & $-0.010(-2.1)$ & $-0.005(-0.9)$ \\
Pack-years (current smokers, $\left.\times 10^{-3}\right) \ddagger$ & $-0.018(-2.8)$ & $-0.009(-1.3)$ \\
Pack-years (ex-smokers, $\left.\times 10^{-3}\right) \ddagger$ & $-0.017(-2.4)$ & $-0.016(-2.0)$ \\
France $v$ UK & $0.002(-0.0)$ & $-0.271(-4.7)$ \\
Germany $v$ UK & $-0.034(-0.3)$ & $-0.405(-3.1)$ \\
Additional age slope (France) & $0.012(3.2)$ & $0.010(2.4)$ \\
Additional age slope (Germany) & $0.006(0.8)$ & $-0.001(-0.1)$ \\
Additional height slope (France) & $0.020(3.1)$ & $0.020(2.7)$ \\
Additional height slope (Germany) & $0.004(0.3)$ & $0.001(0.1)$
\end{tabular}

*Constant refers to a 40 year old non-smoker, height $170 \mathrm{~cm}$, weight $75 \mathrm{~kg}$, from the United Kingdom.

†Smoking intercepts refer to smokers with cumulative amount smoked (pack-year) of 4000. $\ddagger$ Pack-year=total number of packs of 20 cigarettes smoked.

Results from linear regression models showing coefficient (t value).

exclusion or not of five subjects with costophrenic angle obliteration only.

Among those probably exposed occupationally to asbestos, the results were less clear because of confounding between two indices of time since first exposure to asbestos (exposed anywhere or exposed at the plants), time since first exposure to RCFs, and age. Time since first exposure to asbestos anywhere is logically the more relevant of the two asbestos indices, but there are problems with its accuracy, and it was relatively highly correlated with age. Time since first exposure to asbestos in the industry is more accurate, and relates especially to the exposure of those involved in asbestos production at some plants many years ago, but it ignores other exposure to asbestos and was highly correlated with time since first exposure to RCFs.

When, following the method of Cowie et al (1999),${ }^{6}$ adjustment was through time since first exposure to asbestos within the industry, there was a strong effect of asbestos and little evidence of an association between time since first exposure to RCFs and pleural plaques or changes. When, alternatively, adjustment was through time since first exposure to asbestos anywhere, there was a weak effect of asbestos but a significant association between time since first exposure to RCFs and both pleural plaques and pleural changes, whether or not age was also included in the model.
LUNG FUNCTION

Spirometry

Of the 774 subjects 769 provided three technically satisfactory forced expirations, and for $92 \%$ and $94 \%$ respectively the two highest $\mathrm{FEV}_{1} \mathrm{~s}$ and FVCs were within $5 \%$ or $100 \mathrm{ml}$ of each other. As expected, lung function levels were lower among women, older subjects, and smokers, and increased with height (table 9: results for men). There was a significant interaction between age and country and between height and country with the rate of decrease with age less steep among workers from the French plants and the increase with height greater among the French workers.

\section{Transfer factor}

Of the 771 duplicate tests completed only 43 (6\%) differed by more than $10 \%$ of the highest value. The $\mathrm{TL}_{\mathrm{CO}}$ was lower among women and among older workers. Levels were also reduced for current smokers.

\section{LUNG FUNCTION AND EXPOSURE}

Among current male smokers, $\mathrm{FEV}_{1}$ was inversely related to exposure for all exposure variables, but most strongly for respirable fibres (table 10). The association with non-respirable fibres may be due principally to the high correlation between exposures to respirable and nonrespirable fibres. A similar pattern was found for FVC, although the effects were of borderline significance for exposure variables other than respirable fibres. On average the estimated effect in male smokers was mild, predicting a loss of about $100 \mathrm{ml} \mathrm{FEV}_{1}$ or FVC for average exposure to $\mathrm{RCFs}$ of $5 \mathrm{f}^{-\mathrm{ml}^{-1}}$.y. These associations were examined across calendar periods; $\mathrm{FEV}_{1}$ and FVC were inversely associated with exposure to respirable fibre across the range of calendar periods studied.

Results for women were based on 82 workers only. However, $\mathrm{FEV}_{1}$ (and to a lesser extent FVC) was again associated with cumulative exposure to respirable fibres, but in women more strongly to respirable and total dust (table 10). There was some evidence that these associations were strongest for the few women who were current and ex-smokers, particularly for respirable dust. However, this could not be determined reliably due to small numbers.

Table $10 \mathrm{FEV}_{1}(\mathrm{l}), \mathrm{FVC}$ (l), association with cumulative exposure indices

\begin{tabular}{|c|c|c|c|c|}
\hline \multirow[b]{2}{*}{ Exposure } & \multicolumn{3}{|l|}{ Men } & \multirow{2}{*}{$\begin{array}{l}\text { Women } \\
\text { All }\end{array}$} \\
\hline & Non-smokers & Current smokers & Ex-smokers & \\
\hline \multicolumn{5}{|l|}{$\mathrm{FEV}_{1}(1):$} \\
\hline Respirable fibres $\left(\mathrm{f} \cdot \mathrm{ml}^{-1} . \mathrm{y}\right)$ & $0.036(0.8)$ & $-0.118(-3.1)$ & $-0.011(-0.2)$ & $-0.074(-2.6)$ \\
\hline Non-respirable fibres $\left(\mathrm{f} \cdot \mathrm{ml}^{-1} . \mathrm{y}\right)$ & $0.123(0.4)$ & $-0.523(-2.2)$ & $-0.139(-0.5)$ & $-0.455(-2.50)$ \\
\hline Respirable dust $\left(\mathrm{mg} \cdot \mathrm{m}^{-3} \cdot \mathrm{y}\right)$ & $0.022(0.5)$ & $-0.088(-2.2)$ & $-0.005(-0.1)$ & $-0.137(-2.5)$ \\
\hline Total dust $\left(\mathrm{mg} \cdot \mathrm{m}^{-3} \cdot \mathrm{y}\right)$ & $-0.001(-0.1)$ & $-0.027(-2.0)$ & $-0.001(-0.1)$ & $-0.043(-2.9)$ \\
\hline Time in production $(\mathrm{y})$ & $0.024(0.1)$ & $-0.057(-2.4)$ & $-0.014(-0.6)$ & $-0.069(-1.9)$ \\
\hline \multicolumn{5}{|l|}{ FVC (1): } \\
\hline Respirable fibres (f.ml $\left.{ }^{-1} . \mathrm{y}\right)$ & $0.039(0.8)$ & $-0.121(-2.8)$ & $0.021(0.4)$ & $-0.057(-1.6)$ \\
\hline Non-respirable fibres(f. $\left.\mathrm{ml}^{-1} \cdot \mathrm{y}\right)$ & $0.177(0.5)$ & $-0.513(-1.9)$ & $-0.098(-0.3)$ & $-0.365(-1.6)$ \\
\hline Respirable dust $\left(\mathrm{mg} \cdot \mathrm{m}^{-3} \cdot \mathrm{y}\right)$ & $0.021(0.4)$ & $-0.074(-1.6)$ & $-0.010(-0.2)$ & $-0.140(-2.0)$ \\
\hline Total dust $\left(\mathrm{mg} \cdot \mathrm{m}^{-3} \cdot \mathrm{y}\right)$ & $0.001(0.1)$ & $-0.026(-1.7)$ & $0.002(0.1)$ & $-0.036(-2.0)$ \\
\hline Time in production $(\mathrm{y})$ & $-0.002(-0.1)$ & $-0.052(-1.9)$ & $0.002(0.1)$ & $-0.074(-1.7)$ \\
\hline
\end{tabular}

Each index fitted in a separate regression model also including the terms shown in table 9 .

Table shows coefficients/ 5 units exposure ( $t$ value)

$t \geqslant 2.0$ indicates significance at the $5 \%$ level. 
Table 11 Prevalence (n (\%)) of symptoms by sex, age group, country, and smoking

\begin{tabular}{|c|c|c|c|c|c|c|}
\hline & $\begin{array}{l}\text { Chronic } \\
\text { bronchitis }\end{array}$ & $\begin{array}{l}\text { Usual cough or } \\
\text { phlegm }\end{array}$ & Breathlessness & $\begin{array}{l}\text { Recurrent chest } \\
\text { illness }\end{array}$ & $\begin{array}{l}\text { Pleuritic chest } \\
\text { pain }\end{array}$ & $n$ \\
\hline \multicolumn{7}{|l|}{ Sex: } \\
\hline Men & $23(3.3)$ & $168(24)$ & $22(3.2)$ & $22(3.2)$ & $12(1.7)$ & 692 \\
\hline Women & $2(2.4)$ & $16(20)$ & $7(8.5)$ & $6(7.3)$ & $1(1.2)$ & 82 \\
\hline \multicolumn{7}{|l|}{ Age: } \\
\hline$<35$ & $6(2.4)$ & $48(19)$ & $2(0.9)$ & $9(3.6)$ & $1(0.4)$ & 247 \\
\hline $35-44$ & $5(2.2)$ & $63(27)$ & $11(4.7)$ & $10(4.3)$ & $7(3.0)$ & 232 \\
\hline $45-54$ & $8(4.3)$ & $41(22)$ & $5(2.7)$ & $5(2.7)$ & $4(2.2)$ & 195 \\
\hline$\geqslant 55$ & $6(5.5)$ & $32(29)$ & $11(10.0)$ & $4(3.6)$ & $1(0.9)$ & 110 \\
\hline \multicolumn{7}{|l|}{ Country: } \\
\hline England & $6(1.7)$ & $68(19)$ & $7(1.9)$ & $16(4.4)$ & $4(1.1)$ & 362 \\
\hline France & $18(5.1)$ & $93(27)$ & $18(5.1)$ & $6(1.7)$ & $7(2.0)$ & 351 \\
\hline Germany & $1(1.6)$ & $23(38)$ & $4(6.5)$ & $6(9.8)$ & $2(3.3)$ & 61 \\
\hline \multicolumn{7}{|l|}{ Smoking: } \\
\hline Non-smokers & $6(2.1)$ & $48(16)$ & $7(2.4)$ & $8(2.7)$ & $5(1.7)$ & 292 \\
\hline Current smokers & $12(4.3)$ & $103(37)$ & $12(4.3)$ & $12(4.3)$ & $6(2.1)$ & 282 \\
\hline Ex-smokers & $6(3.1)$ & $31(16)$ & $10(5.1)$ & $8(4.1)$ & $2(1.0)$ & 196 \\
\hline
\end{tabular}

Among both men and women there was no overall effect of exposure on $\mathrm{TL}_{\mathrm{CO}}$. However, there was evidence among women of an inverse association between various exposures and alveolar volume $\left(\mathrm{V}_{\mathrm{A}}\right)$ which, although based on small numbers, was consistent with the results for $\mathrm{FEV}_{1}$ in this group.

RESPIRATORY SYMPTOMS

Prevalence of respiratory symptoms conventionally analysed (chronic bronchitis, breathlessness, recurrent chest illness, and pleuritic chest pain) was generally low (table 11). Prevalence of the mild symptom of usual cough or phlegm was not surprisingly higher. The definition of these symptoms is given in the appendix. Prevalence of chronic bronchitis and breathlessness increased with age and was higher among smokers. The prevalence of symptoms varied across countries (table 11 ).

Only 25 subjects reported symptoms of chronic bronchitis, which were not significantly related to any exposure variables. However the odds of reporting such symptoms increased with increasing recent exposure (1986-96) to respirable fibres (table 12). The association with recent exposure was of similar magnitude and of borderline significance for the more general, but related, symptom of usual cough or phlegm which was reported more often (table 12).

For breathlessness, the strongest exposure effects were for recent exposure, for which the ORs were increased (close to 2 ) but not significant. Recurrent chest illness was significantly associated with cumulative exposure to respirable fibres, but not significantly associated with recent exposure. Self reported pleuritic chest pain, was associated with cumulative exposures to fibres and, to a lesser extent, to dust with an OR of $1.43 / 5 \mathrm{f}^{\mathrm{ml}} \mathrm{m}^{-1} . \mathrm{y}$ exposure to respirable fibres (table 12). Nine (69\%) of the 13 subjects reporting this chest pain had been potentially

Table 12 Results from logistic regression analysis of respiratory symptoms relative to exposure to cumulative respirable fibres

\begin{tabular}{lll}
\hline Symptom & $\begin{array}{l}\text { Cumulative exposure } \\
\text { OR }(95 \% \text { CI })\end{array}$ & $\begin{array}{l}\text { Recent exposure (1987-1996) } \\
\text { OR }(95 \% \text { CI })\end{array}$ \\
\hline Chronic bronchitis & $1.28(0.94$ to 1.74$)$ & $1.62(0.74$ to 3.56$)$ \\
Usual cough or phlegm & $1.10(0.92$ to 1.31$)$ & $1.50(0.99$ to 2.25$)$ \\
Breathlessness & $1.18(0.88$ to 1.56$)$ & $1.82(0.92$ to 3.62$)$ \\
Recurrent chest illness & $1.48(1.11$ to 1.96$)$ & $1.42(0.57$ to 3.58$)$ \\
Pleuritic chest pain & $1.43(0.99$ to 2.07$)$ & $1.93(0.72$ to 5.20$)$ \\
\hline
\end{tabular}

OR $(95 \% \mathrm{CI})$ are $/ 5 \mathrm{f} \cdot \mathrm{ml}^{-1} \cdot \mathrm{y}$ exposed to asbestos, compared with 402 (53\%) of the 761 without pain (a non-significant difference).

\section{Discussion}

Although there is recent evidence from animal studies that RCFs may have longer term fibrogenic and carcinogenic potential, ${ }^{15-18}$ previous epidemiological studies of both European and United States employees in the RCF industry are at best equivocal about the role of inhaled RCF material in contributing to fibrotic lung disease. Recent morbidity and mortality studies in Europe and the United States are intended to provide more soundly based and coordinated evidence as to whether airborne RCFs at current and past concentrations of exposure pose a real threat to respiratory health among the workforce.

The medical survey for the current study took place almost 10 years after the first European survey of RCF workers. These workers have therefore experienced up to 10 more years of occupational exposure to RCF materials, thereby increasing the power of the study to detect effects. A further assessment of current airborne concentrations of fibres and dust, and changes of concentration since the last survey, providing information from two time points, has increased the reliability of the exposure estimates. The lung function tests have been expanded since the previous survey to include measurement of transfer factor as well as spirometric variables, and a full lifetime occupational history and respiratory symptoms and smoking questionnaire have been collected at survey by trained interviewers.

Measurements from an earlier occupational hygiene survey and during the current study ${ }^{11}$ have allowed a reliable estimation of worker's recent exposures. However estimates of exposure before 1987 are much less reliable. Based on a limited pilot study, it was found to be not practicable to reconstruct reliably the concentrations of fibres and dusts in the various occupations and factories before 1987 and so the principal analyses of this study used indices of cumulative exposure derived as if concentrations in 1987 had applied in earlier years also, although it was widely thought that concentrations in earlier years had been higher. 
The possible effects of this underestimation on the study's ability to detect associations were explored in a small supplementary exercise. Other exposure indices were constructed, designed to give greater weighting to earlier exposures - for example, assuming that exposures before 1971 were three times as high as in 1987 and exposures 1972-86 were twice as high — and some key analyses were repeated. This weighting compensates for either or both of two relevant factors: possible underestimation of exposures in earlier periods, and greater biological relevance (per unit exposure) of earlier rather than recent exposures - one way of expressing latency. In these additional analyses, the significance of the findings changed little, compared with using the main exposure index, and so results have not been presented in detail here. The exercise provides reassurance that the use of a relatively simple index of cumulative exposure has not seriously degraded the power of the study to detect relations between health and long term exposure to RCFs. The supplementary analyses did of course suggest lower effects per unit exposure than in the main analyses which we have reported.

We need also to consider the effect of including by design only current workers in 1987, and the low participation rates of workers who left after 1987 in the present study. Less healthy workers may preferentially leave an industry, or move to jobs with lower exposure within it, if their ill health is noticeable and especially if they think that it has been affected by their work. This would lead to an underestimation of the overall levels of ill health in the industry. The principal focus in the present study has been on exposureresponse relations, and these relations may be robust to health related selection even when prevalences are clearly affected. ${ }^{19}$ Also, in the present industry, levels of noticeable respiratory ill health were low among those studied in $1987^{1}$ and again in the present study. For example, small opacities $0 / 1$ or $1 / 0$ are not indicative of other changes to health that a worker would identify and attribute to work. It is most likely then that any health related selection out of the industry, non-participation in the study, or movement of jobs within the industry has been small and has not distorted to any appreciable extent our findings on exposure-response relations.

The comprehensive statistical analyses have provided a systematic exploration of the medical and exposure data in different periods and subgroups, based on an understanding of the possible mechanisms of the development of lung disease. In particular, if exposure to ceramic fibres did indeed contribute to fibrosis in exposed workers, then any associated radiological or lung function changes, and some respiratory symptom effects, would be expected to develop slowly and would not become apparent without several years of exposure, maybe 10 or more. In practice some of the findings have shown or suggested associations between occupational exposure and indices of respiratory health, whereas many others have not, making the results difficult to interpret coherently.
PLEURAL CHANGES, INCLUDING PLEURAL PLAQUES The results for pleural changes were not clear cut and were limited both by coexposure to asbestos and the relative newness of the RCF industry in Europe. Among the 355 workers unexposed occupationally to asbestos, the latency time for exposure to RCFs was short (average 9.6 years since first exposure to RCFs), and only nine subjects had pleural plaques. Nevertheless, for both pleural changes and pleural plaques, there was some evidence of a relation with time since first exposure to RCFs. Among those probably exposed occupationally to asbestos, it was difficult to separate the effects of exposure to asbestos and RCFs. Results, although sensitive to what index of time since first exposure to asbestos was used, were consistent with an effect of time since first exposure to RCFs. No association was found with duration or intensity of exposure to RCFs.

Concurrent studies of RCF workers in the United States have more statistical power to detect effects clearly. There, subjects had longer latency times for exposure to RCFs and only a small proportion had also been exposed to asbestos. The United States results showed an association between presence of pleural plaques and indices of exposure to RCFs, not only unadjusted for age, ${ }^{4}$ but also after adjustment for age and exposure to asbestos. ${ }^{20}$ The results from the present study are less clear than, but consistent with, these United States findings.

\section{SMALL OPACITIES}

It is well known that experienced and authoritative film readers can differ substantially in their classification of small opacities on radiographs, even when (as here) they read to a standardised protocol, based on the ILO (1980) classification and using the ILO standard films. Also, in general population studies, whereas most people are categorised as $0 / 0$, a considerable proportion (the figure varying from study to study) may be categorised as $0 / 1$ or higher. ${ }^{21}$ Nevertheless, the prevalence of small opacities as classified in the recent films from the present study was unusually high, for both exposed and non-exposed workers, with films from about half of those studied rated as category $0 / 1$ or more (median classification, three readers).

The purpose of the present study was to identify possible exposure-response relations between various indices of respiratory health and past exposure to RCFs, taking account of other factors. The estimation of prevalences was of interest but was not the principal focus. We need to be sure, however, that the reported high prevalence does not invalidate the exposure-response findings. There are three principal considerations.

Firstly, the present film readings do show some expected relations, specifically with age and smoking. In the general population, category $0 / 1$ radiographs are found more often in older people and in smokers ${ }^{22}$ indicating that in many cases the opacities do represent a real anatomical change (although, as noted earlier, not a change of which the subject would be aware other than through radiology and film 
classification). In the current study, prevalences of small opacities category $0 / 1$ and $1 / 0$ also increased with age and were higher among current and ex-smokers than among nonsmokers, suggesting that the classifications, although high, do point to something real.

Secondly, we do by design have, internal to the study, a check on the readers' baseline classifications of abnormality. A small set of 164 radiographs of workers unexposed to dust or fibres, previously classified by a different panel of medical readers, had been included randomly in the films to be classified, specifically for purposes of comparison. In the event, all three readers now recorded a higher prevalence of small opacities, of low category, than were seen in the previous readings by the different panel. Perhaps more importantly, limited comparisons (unadjusted for age and smoking) showed similar prevalence of small opacities in the 1996 films of RCF workers compared with that in the unexposed workers, suggesting that exposure to RCFs was not a major cause of the opacities in the recent films of RCF workers.

On the other hand, and thirdly, the readers found a substantially lower prevalence of small opacities in the 1987 films of RCF workers than in either the 1996 films of RCF workers or those of workers not exposed to dust. We do not know why this difference in profusion is so marked, but think that it may be principally a reading artefact associated with film appearance and quality rather than a real increase in frequency of small opacities. The 1987 radiographs were smaller in appearance than the other films, whereas the 1996 films and those of the workers not exposed to dust were not clearly distinguishable from one another. Also, the earlier RCF films were taken with different equipment, and lower $\mathrm{kV}$, than the other two sets of films.

It would seem then that the high prevalence of small opacities in the recent films of RCF workers is not in itself strong evidence that exposure to RCFs is implicated. The main evidence, however, was intended to come from, and did come from, logistic regression analyses of small opacities relative to various indices of exposure to RCFs. These showed some significant associations, but in a time related pattern which is not plausible biologically. Specifically, there was a relation of small opacities generally with early exposure, and with recent exposure, but not with exposure in the intermediate years. There are strong reasons to be suspicious about whether this points to a true effect of fibres. Most of these reasons are internal to our study; we note that the United States study identified a strong, but non-significant trend between models of exposure to RCFs and interstitial changes. ${ }^{4} 20$

In the time specific analyses of the present study, the highest coefficient was for exposure up to 1971 , but this finding was based on very few data: only 51 men exposed up to 1971, and most of these in occupations with low levels of exposure. Average estimated exposures for these early years (based on 1987 concentration data) were therefore also relatively low. By contrast, most of the participants had some potential exposure to RCF materials in the 5 years immediately preceding the medical survey and so the associations between radiology and very recent exposures are not dependent on results from a few people. These associations with exposure since 1992 are however implausible as causative associations, because time from exposure to medical survey is too short given that recent exposures are very low (current concentrations of respirable fibres $0.03-1.25$ fibres. $\mathrm{ml}^{-1}$, current concentrations of respirable dust $0.08-0.42$ $\left.\mathrm{mg} \cdot \mathrm{m}^{-3}\right)$. Also, if recent low exposures really did contribute to the development of small opacities, then we would have expected that earlier exposures would have resulted in higher prevalence of category 1 or more small opacities in 1987 than indeed was found.

No associations were apparent or strongly suggested between radiological signs and exposures incurred in the intermediate period 1976-91 when many in the study were exposed, although some association between category $0 / 1+$ (but not $1 / 0+$ ) and years of production in this period was suggested. We would have expected clear associations with exposure in these intermediate years if exposure before 1971 did have a real and noticeable effect. It is possible that if the effect before 1971 were real, an association with exposures subsequently might not be found if airborne concentrations had been reduced markedly, and if the mechanism of damage depended on exceeding a concentration threshold instead of, or in addition to, depending on cumulative exposure. There is no evidence for either of these conditions; their joint occurrence seems implausible.

\section{LUNG FUNCTION AND SYMPTOMS}

The most clear cut finding concerns $\mathrm{FEV}_{1}$ and FVC in men, among whom associations were found with cumulative exposure, especially to respirable fibres, although in current smokers only. By contrast with the radiology results, the effects of exposure on lung function were apparent across all the calendar periods studied. Among the women a stronger association with dust in current and ex-smokers was also indicated.

We are unsure of the mechanisms behind this effect. It is consistent with a non-specific response among smokers to the burden of respirable dust. However, such an effect is puzzling, given the relatively low concentrations of respirable dust $\left(0.08-0.42 \mathrm{mg} . \mathrm{m}^{-3}\right)$ in recent years. Mild fibrosis could give a similar pattern of functional relations to those found; however, the radiological results give no strong evidence of fibrosis related to exposure in the workforce. Nor does the present study give insight into why associations between lung function and exposure might be confined to current smokers and, given the United States and earlier European results, possibly ex-smokers only. Damage from smoking might make the lung tissue more vulnerable to other inhaled substances. If this were so, we might expect a higher coefficient per unit exposure to dust among heavier smokers. Limited analyses, although by no means compelling, are broadly supportive of such a pattern. Overall, however, the 
consistency of association across calendar periods of exposure in the present study, and consistency with the earlier European and United States studies, suggest that there is a real, although on average mild, effect of exposure on lung function in smokers.

There was evidence of an association of recent exposure with chronic bronchitis and with usual cough or phlegm which could be due to an irritative effect of RCFs. There could also be a reporting artefact of workers in currently dusty jobs tending to report more symptoms. An association between recurrent chest illnesses and cumulative exposures was found, but prevalence in the study group was low. A relation between cumulative exposure and pleuritic chest pain was also suggested. The number of cases was small. These symptoms might have been the result of pleurisy, or of musculoskeletal chest wall pain. We have no information on whether physical activity in some jobs might have influenced chest pain of this kind. As for cough or phlegm, reporting might have been influenced by knowledge of dusty conditions.

RELEVANT EXPOSURE TO RCFS AND NATURE OF THE RESPONSE

The concentrations on which the exposure variables are based are correlated, and time worked in the industry has a major influence on all cumulative exposures. Where associations between exposures within the RCF industry and health have been identified, it has not been possible to attribute them convincingly to fibres rather than dust, or conversely. However, the evidence points to respirable RCFs at least as much as to respirable or total dust, especially so for lung function in male smokers, where overall the evidence of a relation with exposure is strongest.

\section{Conclusions}

No association was found between category $1 / 0+$ opacities and exposure. A weak association between category $0 / 1+$ small opacities and cumulative exposure to respirable RCFs was suggested but not clearly established, and relations over calendar periods were implausible biologically. Pleural changes, after adjustment for age and past exposure to asbestos, showed some evidence, although not significant, of a relation with time since first exposure to RCFs. Among men, $\mathrm{FEV}_{1}$ and FVC were inversely related to estimated cumulative exposure to respirable fibres, but only in current smokers, and suggest a restrictive lung defect. The prevalence of self reported chronic chest illnesses increased with cumulative exposure. Although these relations are relatively mild and, in some cases, ambiguous, we consider it would be prudent to continue to keep dust and fibre concentrations as low as possible and to discourage smoking.

This study was funded by the European Ceramic Fibres Industry Association. The radiographs were read epidemiologically by Professor Anthony Seaton, Professor Kurt Hering, and Professor Patrick Brochard. We thank all current and former workers at the Patrick Brochard. We thank all current and former workers at the plants who attended the medical surveys and all personnel at the plants and in the survey team who helped to ensure that the sur-
veys ran smoothly. Helpful comments were received from many veys ran smoothly. Helpful comments were received from many colleagues on the research
institutions and elsewhere.

\section{Appendix: Definition of respiratory} symptoms

CHRONIC BRONCHITIS

Persistent cough and phlegm for 3 consecutive months for 2 or more years.

USUAL COUGH OR PHLEGM

Positive answer to "Do you usually cough?" or "Do you usually bring up phlegm from your chest?"

\section{BREATHLESSNESS}

Positive answer to "Do you have to walk more slowly on level ground than people of your own age because of shortness of breath?" or "Do you ever have to stop for breath when walking at your own pace on level ground?".

\section{RECURRENT CHEST ILLNESS}

At least two chest illnesses with phlegm in the past 3 years which kept the worker off work.

\section{PLEURITIC CHEST PAIN}

A sharp shooting pain in the chest or chest and shoulder, lasting longer than 6 hours, which got worse when taking a deep breath, laughing or coughing and which occasioned a visit to the doctor.

1 Trethowan WN, Burge PS, Harrington JM, et al. A study of the respiratory health of employees in seven European ceramic fibre manufacturing plants. Final report to the European Ceramic Fibre Industries Association (ECFIA). Birmingham: Institute of Occupational Health, 1989.

2 Trethowan WN, Burge PS, Rossiter CE, et al. Study of the respiratory health of employees in seven European plants that manufacture ceramic fibres. Occup Environ Med 1995; 52:97-104.

3 Burge PS, Calvert IA, Trethowan WN, et al. Are the respiratory health effects found in manufacturers of ceramic fibres due to the dust rather than the exposure to fibres? Occup due to the dust rather than
Environ Med 1995;52:105-9.

4 Lockey J, Lemasters G, Rice C, et al. Refractory ceramic fiber exposure and pleural plaques. Am $\mathcal{f}$ Resp Crit Care Med 1996;154:1405-10.

5 Lemasters G, Lockey JE, Levin LS, et al. An industry wide pulmonary study of men and women manufacturing refractory ceramic fibres. Am F Epidemiol 1998;148:910-19.

6 Cowie HA, Beck J, Wild P, et al. Epidemiological research in the European ceramic fibre industry 1994-8. Vol 2. A study of the respiratory health of workers in the $R C F$ industry. Edinburgh: Institute of Occupational Medicine, 1999. (IOM report TM/99/01.)

7 International Labour Office. Guidelines for the use of ILO International classification of radiographs of pneumoconiosis. Geneva: ILO, 1980 . (Occupational Safety and Health Series, No 22, Rev 80.)

8 Quanjer P, ed. Standardized lung function testing. Report Working Party. Luxembourg: Commission of the European Communities. Bulletin Europeen de Physiopathologie Respiratoire 1983;19(suppl 5)).

9 Ferris BJ. Epidemiology standardization project. New York: American Lung Association. Am Rev Respir Dis 1978;118(6 part 2).

10 Medical Research Council. Questionnaire on respiratory symptoms. London: MRC, 1986.

11 Groat S, Kauffer E, Lovett $M$ et al. Epidemiological research in the European ceramic fibre industry 1994-8. Vol 1. Workplace concentrations of airborne dust and fibres. Edinburgh: Institute of Occupational Medicine, 1999. (IOM Report TM/99/01).

12 Draper NR, Smith H. Applied regression analysis, 3rd ed. New York: John Wiley, 1998.

13 Hosmer DW, Lemeshow S. Applied logistic regression. New York: John Wiley, 1989.

14 Hastie TJ, Tibshirani RJ. Generalized additive models. London: Chapman and Hall, 1990.

15 Mast RW, McConnell EE, Hesterberg TW, et al. Multiple dose chronic inhalation toxicity study of size separated dose chronic inhalation toxicity study of size separated
kaolin refractory ceramic fiber in male Fischer 344 rats. Inhal Toxicol 1995; 7:469-502.

16 McConnell EE, Hesterberg TW, Chevalier J, et al. Chronic inhalation toxicity of a kaolin based refractory ceramic fiber in Syrian Hamsters. Inhal Toxicol 1995;7:503-32.

17 Bunn WB, Bender JA, Hesterberg TW, et al. Recent studies of man-made vitreous fibres. F Occup Med 1993;35:101-13.

18 Brown RC, Sebastien P, Bellmann B, et al. Particle contamination in experimental fibre preparations.

19 Gauld SJ, Hurley JF, Miller BG. Differences between long term participants and non-responders in a study of coalminers' respiratory health and exposure to dust. Ann Occup Hyg 1988;32(suppl 1):545-51.

20 Lockey J, Lemasters G, Levin L, et al. A longitudinal study of chest radiographic changes of workers in the refractory ceramic fiber industry. Chest 2001 (in press).

21 Impivaara $\mathrm{O}, \mathrm{Zitting} \mathrm{AJ}$, Kuusela $\mathrm{T}$, et al. Observer variation in classifying chest radiographs for small lung opacities and pleural abnormalities in a population sample. Am f Ind Med 1998;34:261-5.

22 Weiss W. Cigarette smoking and small irregular opacities. $\mathrm{Br}$ f Ind Med 1991;48:841-4. 